\title{
Maternal Stressful Experience in Giving Birth to Premature Baby in Neonatal Intensive Care Unit Ward
}

\author{
Andi Fatmawati Syamsu ${ }^{1,2 *}$, A. Dwi Bahagia Febriani ${ }^{3}$, Ema Alasiry $^{3}$, Kadek Ayu Erika $^{4}$, Andi Mardiah Tahir $^{5}$, Isharyah Sunarno ${ }^{5}$ \\ ${ }^{1}$ Student of Doctoral Program, Faculty of Medicine, Universitas Hasanuddin, Makassar, Indonesia; ${ }^{2}$ Department of Nursing, \\ Poltekkes Kemenkes Palu, Palu, Indonesia; ${ }^{3}$ Department of Pediatrics, Faculty of Medicine, Universitas Hasanuddin, Makassar, \\ Indonesia; ${ }^{4}$ Department of Pediatric, Faculty of Nursing, Universitas Hasanuddin, Makassar, Indonesia; ${ }^{5}$ Department of \\ Obstetrics and Gynecology, Faculty of Medicine, Dr. Wahidin S. Husodo Hospital, Makassar, Indonesia
}

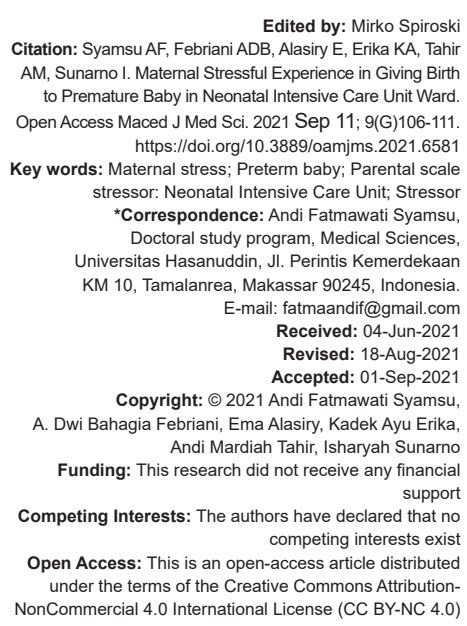
$\begin{aligned} & \text { Edited by: Mirko Spiroski } \\ & \text { Citation: Syamsu AF, Febriani ADB, Alasiry E, Erika KA, Tahir }\end{aligned}$ Citation: Syamsu AF, Febriani ADB, Alasiry E, Erika KA, Tahir
AM, Sunarno I. Maternal Stressful Experience in Giving Birth to Premature Baby in Neonatal Intensive Care Unit Ward. Open Access Maced J Med Sci. 2021 Sep 11; 9(G)106-111. https://doi.org/10.3889/oamjms.2021.6581 Key words: Maternal stress; Preterm baby; Parental scale stressor: Neonatal Intensive Care Unit; Stressor "Correspondence: Andi Fatmawati Syamsu, Doctoral study program, Medical Sciences, Universitas Hasanuddin, Jl. Perintis Kemerdekaan KM 10, Tamalanrea, Makassar 90245, Indonesia. E-mail: fatmaandif@gmail.com Received: 04-Jun-202 Revised: 18-Aug-202 Accepted: 01-Sep-202 Copyright: ๑) 2021 Andi Fatmawati Syamsu A. Dwi Bahagia Febriani, Ema Alasiry, Kadek Ayu Erika, Andi Mardiah Tahir, Isharyah Sunarno
Funding: This research did not receive any financial Competing Interests: The authors have declared that no competing interests exis Open Access: This is an open-access article distributed under the terms of the Creative Commons AttributionNonCommercial 4.0 International License (CC BY-NC 4.0)

\begin{abstract}
AIM: This study aimed to determine the stressor of mothers whose baby was treated in Neonatal Intensive Care Unit (NICU) ward and identify the demography parameter which affected the stressor.

METHODS: This cross-sectional study was done in four hospitals in Makassar City. Stressor was evaluated using Parental Scale Stressor (PSS): NICU. Samples were taken consecutively for 30 babies treated in NICU ward for more than $24 \mathrm{~h}$.

RESULTS: On the average, the mothers' stressors were the situation and view of NICU (2.87), appearance and behavior of the baby (2.78), the role of parents (2.74), and communication relationship between the parents and nurse (2.80). Meanwhile, demography factors (maternal age, age of pregnancy, parity, and experience) did not affect the maternal stress statistically.

CONCLUSION: Premature babies who are treated in NICU ward can be the source of maternal stress, thus provision of education to the mothers can decrease the stress.
\end{abstract}

\section{Introduction}

Neonatal Intensive Care Unit (NICU) becomes an environment which has the potential to cause stress on premature babies' mother. Maternal stress is related to babies who born premature, medical condition of the baby, complexity of NICU environment, concern of babies vulnerability, and stress due to normal transmission process of becoming a mother [1]. In addition to, stress related to normal transmission of becoming a mother, stress due to the environment of neonatal treatment also becomes the main factor contributing to the maternal stress [2].

Babies who are treated in NICU ward are a source of stress and worry of the mothers. Neonatal environment stress which becomes the source of maternal stress include the treatment process in NICU, including the difficulty in meeting the role of mother/ parents and medical equipment used for the intervention and behavioral pattern of the medical staff [3], [4].
Such condition is proven by the result of the research conducted by Ashawani et al. (2017) who identified stress level among parents/mothers who had babies treated in NICU. Ashawani identified that the average situation in NICU, the appearance and behavior of the baby, changes in the role of parents/mother, as well as communication relationship between the parents and nurses significantly affected the maternal stress.

The treatment of premature newborn in NICU ward affects the baby since the bonding between the mother and baby does not occur when the baby is treated in NICU. Physical and psychological closeness between the parents and baby through interaction can decrease stress to the parents. Parents' bonding actively helps the baby's development and growth. Furthermore, mother has large commitment in taking care of their premature baby in NICU ward. Long inpatient condition in NICU often emerges interaction between the parents and baby [5]. Meanwhile, the effect on the mother is that since the mother views this in several perspectives, some of the mothers will see the 
positive side of this situation in which the baby obtains treatment needed since he was born, while some other mothers view this as negative when the baby or staff is not in accordance with the expectation. Poor condition, especially maternal stress, can affect the growth and development of the babies [1].

Research conducted by Musabirema, Brysiewicz, and Chipps (2015) described and analyzed the perception of parents' stress when they had babies treated in NICU in Kigali, Rwanda. Qualitative survey was applied to measure the stress level using PSS: NICU. The result showed that the most stressful incident is the appearance and behavior of the babies with mean score of 4.02 . Meanwhile, the sub-scale item related to the environment and sound obtained mean score of 2.51. In addition, this research also found that age, education level, occupation, and babies' weight were related to the parent stress [6].

Maternal stress due to the experience with the baby treated in NICU ward has been documented in several literatures. However, the literature review regarding the stress condition is rarely found in developing countries [1], [7]. Information related to mothers whose baby has high risk and treated in NICU ward, understanding the mothers' need, intervention planning to meet the family need, and several important matters' to identify factors related to maternal stress as well as the development of effective intervention to increase the mental health on the mothers are still needed to be found.

Several factors including personality, mental health, and family contribute the type and level of stress. Meanwhile, other factors are the function of family, social economy status, and parents' perception on children who are sick [8]. Furthermore, the treatment period of baby in NICU has stressful effect on parents, showing that the longer the baby is treated in the hospital, the higher the stress level [9].

Mothers, in taking care their baby in NICU, cannot be separated from the staff involvement in giving guidance for every intervention that will be done. Health worker must involve the parents as a partner in taking care of the baby [10]. Research that was done by Bostanabad et al. (2017) stated that premature baby who is treated in NICU causes maternal stressor phenomenon, so that support from the family can decrease the stress [11]. Providing education toward the family, especially the mother, can increase mother trust in taking care of the baby when they go home.

Prolonged maternal stress will give psychological disruption on the mother; one of them is post-partum depression or postpartum blues. Postpartum mother who does not get support from their husband will have 6.016 times more opportunity to experience postpartum stress compared to postpartum mother who obtains support from husband [12]. This research result is in line with research conducted by Qiftiyah (2018) that some of postpartum mothers experienced light postpartum blues when they obtained less support from the parents and had poor knowledge [13]. Family is an integral part of developmental care because normal development is difficult to occur without family. An example of such type of NICU care is seen in the Family Integrative Model which is a family-focused model of care, in which nurses support parents through education, guidance and assistance to become primary caregivers in taking care of the neonates [14].

Based on some patients at Hospital of Unhas, Islamic Hospital of Faisal, Regional General Hospital of Labuang Baji, and Hospital of Ibnu Sina for high-risk neonates, it was known that NICU environment was quite stressful for mothers and fathers. The highest score was in the relationship between the babies and parents. Mothers had significantly higher stress scores for each sub-scale and total scale compared to the fathers.

Based on the previous explanation, solution to the psychological problems that occur in postpartum mothers whose babies are treated in NICU is needed. Therefore, there is a requirement for a study to measure the stress level of parents whose babies are treated in NICU based on sub-scales, by comparing sources of stress for mothers and fathers using an observational method evaluated using PSS: NICU.

\section{Materials and Methods}

\section{Design and sampling}

This study was an analytical observational study through a cross-sectional approach which was carried out in four hospitals in Makassar City, those are Hospital of Unhas, Hospital of Faisal, Regional General Hospital of Labuang Baji, and Hospital Ibnu Sina. The research samples were 30 mothers with premature babies who were treated in NICU. The samples were taken using consecutive sampling technique. To become research respondents, mothers were required to fill informed consent. The research was conducted in September to December 2019. To obtain the data about stress, researchers distributed questionnaires to mothers who came to visit their babies in NICU room.

\section{Research instrument}

The measurement of maternal stress used PSS: NICU aiming to measure parents' perceptions of stressors in NICU ward. The instrument consisted of 32 statements with four sub-scales measuring (a) the situation and view of NICU; (b) the appearance and behavior of the baby; (c) the role of parents; and (d) 
the communication relationship between parents and nurses [2], [5]. Respondent response to PSS: NICU was given 4 points on a Likert scale, in which 1 point was given if "the stressor is not significantly felt," point 2 was given if "the stressor is not felt," point 3 if "the stressor is felt," and point 4 if "the stressor is significantly felt." The higher the respondent answer points, the greater the perceived stressor. Demographic data that were asked directly to respondents included maternal age, pregnancy age, parity, and cesarean section experience.

\section{Data analysis}

Data were analyzed using SPSS software. Descriptive analysis was performed on mean and SD for continuous data, frequency, and presentation for categorical data. The data normality test was carried out using Shapiro-Wilk test, obtaining that the data were normally distributed so that it was continued with independent sample $t$-test aiming to see the relationship between demography and maternal stress for two data groups and one-way ANOVA test for three data groups. The $p$-value was considered significant if $<0.05$.

\section{Results}

The mean maternal age who participated in the research was $26.13 \pm 4.8$ years old. As many as, 17 mothers $(56.7 \%)$ were multiparous, meaning that they have given birth for 2-4 times, and most of the mothers $(73.3 \%)$ did not have cesarean section experience.

Babies profile showed that on the average, they were born on the pregnancy age of $31.37 \pm$ 1.8 weeks, 14 babies (46.7\%) were classified as very preterm because they were born at 28-31 weeks of pregnancy, 11 babies (36.7\%) were classified as moderate term in which they were born at 32-33 weeks of gestation, and 5 babies (16.7\%) were classified as late term in which they were born at 34-36 weeks. As many as, 13 babies (43.4\%) were the first children.

The results of the maternal stress analysis based on PSS: NICU (Table 1) shows various stressors felt by mothers when premature babies were in NICU ward. Based on the situation and view in NICU, there were two components that the mother perceived as stressors, those are the sound of the monitor alarm in NICU room and the large number of health workers in the room. Based on the appearance and behavior of the baby, there were five stressors felt by the mothers, those are changes in the baby's skin color, the baby's small size, tube and needle attached to the baby's body, the baby helpless look, and the baby who did not cry.
Table 1: Maternal stressor measured using PSS: NICU $(n=30)$

\begin{tabular}{lll}
\hline Sub-scale and component & Stress score \\
\cline { 2 - 3 } & Mean & SD \\
\hline Situation and Scene in NICU & & \\
The presence of monitor and its equipment & 2.77 & 1.006 \\
The sound of monitor alarm & 3.03 & 0.964 \\
The presence of other premature babies & 2.77 & 0.898 \\
The large number of health workers & 2.30 & 0.915 \\
The presence of ventilator & 3.47 & 0.681 \\
Mean value & 2.87 & 0.595 \\
The appearance and behavior of babies & & \\
Equipment closed to the baby & 2.63 & 0.718 \\
Bruises and incision wound & 2.60 & 0.814 \\
Change of skin color & 3.13 & 0.937 \\
Baby size which is very small & 3.23 & 0.774 \\
Baby wrinkled skin & 2.70 & 0.877 \\
Tube and needle attached & 3.07 & 0.907 \\
Baby food through infusion & 2.20 & 0.484 \\
Baby looks helpless & 3.03 & 0.669 \\
Baby does not cry & 3.33 & 0.606 \\
Baby cries for a long time & 1.70 & 0.877 \\
Baby skin in pale and blue & 2.90 & 0.885 \\
Mean score & 2.78 & 0.285 \\
The role of parents & & \\
Sad because being separated from the baby & 3.07 & 0.691 \\
Baby food is not given by the parents themselves & 2.27 & 0.828 \\
Cannot take care of the baby themselves & 2.90 & 0.607 \\
Cannot hold or carry the baby & 2.77 & 1.006 \\
Helpless feeling & 3.00 & 0.788 \\
Does not have time for the baby & 2.80 & 0.805 \\
Forget with the baby condition & 2.27 & 0.980 \\
Baby cannot be with the family & 2.43 & 1.073 \\
Afraid of touching the baby & 2.90 & 0.803 \\
Health workers are closer with the baby & 3.00 & 0.910 \\
Mean score & 2.74 & 0.362 \\
Communication relationship between the parents and nurse & & \\
Nurse explanation is too fast & 2.73 & 0.785 \\
Does not understand of what being told by the nurses & 3.23 & 0.774 \\
Does not have enough information regarding the baby & 2.90 & 0.803 \\
Nurses rarely speak & 2.03 & 0.765 \\
Nurses provision of information is different & 3.00 & 0.788 \\
Unsure with the information given by the nurses & 2.63 & 0.718 \\
Worry of the baby condition & 3.10 & 0.845 \\
Mean score & 2.80 & 0.322 \\
\hline & & \\
\hline
\end{tabular}

Based on the sub-scale of the parent role, there were three sources of stressors felt by the mother, those are sadness to be separated from the baby, feelings of helplessness, and the view of health workers who were closer to the baby than the mother. Based on the communication relationship between parents and health workers, there were two stressors felt by the mothers, those are the mother did not understand what the nurse said, nurses delivered different information, and the mothers became worried about the baby's condition because she did not understand the baby condition. Among the four PSS: NICU subscales, the one which had the highest mean value was the situation and view of NICU.

Maternal stressor level was related to demographic parameters as shown in Table 2. Based on the age characteristics, there was no difference in stressor levels of mothers aged $<25$ years old and mothers aged $\geq 25$ years old, although the mean scores of sub-scales 2, 3, and 4 were slightly higher in mothers aged $\geq 25$ years. Based on pregnancy age, there was no difference in maternal stressor levels at 28-31 weeks, 32-33 weeks, and 34-36 weeks of pregnancy, although mothers who gave birth at 34-36 weeks of pregnancy had a mean stressor level score on the subscale of situation and view of NICU. Based on parity, it showed that there was no difference in stressor levels of primiparous mothers and multiparous mothers, although the mean score of multiparous mothers was 
Table 2: Maternal Stressor level related to demography parameter

\begin{tabular}{|c|c|c|c|c|c|c|c|c|c|c|}
\hline \multirow[t]{2}{*}{ Characteristics } & \multirow[t]{2}{*}{ Group } & \multirow[t]{2}{*}{$\mathrm{n}$} & \multicolumn{2}{|c|}{$\begin{array}{l}\text { Situation and scene } \\
\text { in NICU }\end{array}$} & \multicolumn{2}{|c|}{$\begin{array}{l}\text { Appearance and } \\
\text { behavior of the baby }\end{array}$} & \multicolumn{2}{|c|}{ Role of parents } & \multicolumn{2}{|c|}{$\begin{array}{l}\text { Communication relationship } \\
\text { between parents and nurses }\end{array}$} \\
\hline & & & Mean (SD) & $p$ & $\begin{array}{l}\text { Mean (SD) } \\
\text { (SD }\end{array}$ & $p$ & Mean (SD) & $\mathrm{p}$ & Mean (SD) & $p$ \\
\hline \multirow[t]{2}{*}{ Maternal age ${ }^{*}$} & $<25$ years old & 15 & $2.87(0.662)$ & 1.00 & $2.75(0.267)$ & 0.65 & $2.68(0.305)$ & 0.373 & $2.76(0.304)$ & 0.475 \\
\hline & $\geq 25$ years old & 15 & $2.87(0.543)$ & & $2.80(0.310)$ & & $2.80(0.412)$ & & $2.85(0.343)$ & \\
\hline \multirow[t]{3}{*}{ Pregnancy age $^{* \star}$} & $28-31$ weeks & 14 & $2.83(0.670)$ & 0.78 & $2.72(0.258)$ & 0.45 & $2.73(0.358)$ & 0.544 & $2.83(0.351)$ & 0.799 \\
\hline & $32-33$ weeks & 11 & $2.84(0.564)$ & & $2.79(0.323)$ & & $2.82(0.382)$ & & $2.82(0.320)$ & \\
\hline & $34-36$ weeks & 5 & $3.04(0.518)$ & & $2.91(0.280)$ & & $2.60(0.354)$ & & $2.71(0.286)$ & \\
\hline \multirow[t]{2}{*}{ Parity* } & Primipara & 13 & $2.89(0.592)$ & 0.84 & $2.78(0.314)$ & 0.99 & $2.74(0.301)$ & 0.984 & $2.74(0.302)$ & 0.316 \\
\hline & Multipara & 17 & $2.85(0.615)$ & & $2.78(0.271)$ & & $2.74(0.411)$ & & $2.86(0.335)$ & \\
\hline \multirow[t]{2}{*}{ Cesarean section experience ${ }^{*}$} & Do not have & 22 & $2.83(0.583)$ & 0.55 & $2.79(0.289)$ & 0.67 & $2.72(0.318)$ & 0.672 & $2.77(0.332)$ & 0.375 \\
\hline & Have & 8 & $2.98(0.654)$ & & $2.74(0.289)$ & & $2.79(0.485)$ & & $2.89(0.293)$ & \\
\hline
\end{tabular}

slightly higher on the sub-scale of the communication relationship between parents and nurses. Based on the caesarean section (SC) experience, it shows that there was no difference in the stressor level of mothers who have never had SC with mothers who have had $\mathrm{SC}$, although the mean score of mothers who have had SC were slightly higher in stressors on subscales 1, 3, and 4 .

Maternal stressor analysis based on PSS:

NICU

\section{Discussion}

The stressor level of mothers whose babies were treated in NICU ward based on PSS: NICU score was mostly triggered by situations and scene in NICU. The foreign condition of the ward for parents caused stress. Two components that caused maternal stress related to the situation and scene in NICU were the sound of the monitor alarm in NICU ward and the number of health workers in the room that they considered as too much. Meanwhile, the appearance and behavior of babies that can be stressor for the mother were changes in the baby's skin color, baby's small size, needles, and tubes attached to the baby's body, and babies who look helpless and babies who did not cry.

The treatment of LBW babies in intensive rooms has a significant effect on parents such as fear, guilt, stress, and anxiety [15], [16]. The parents feel stress when the child is being treated in an intensive ward, especially when the child is in a critical condition and is afraid of losing the loved one, as well as feelings of grief, stress, fear, and anxiety. Parents' feelings of stress should not be ignored because if parents feel stressed, it will make parents unable to take care of their children properly.

Based on the sub-scale of the parent role, there were three sources of maternal stressors felt, those are sadness to be separated from the baby, feelings of helplessness, and views of health workers who were closer to the baby than the mother. The results of this research are in line with the research performed by Rahayuningsih (2012) which analyzed the relationship between parental stress levels in terms of changes in the role of parents on the interaction between the parents and baby. It was found that 28 (75.7\%) parents with low stress level had less interaction with the baby [17]. Meanwhile, among parents who had high stress level, $41(83.7 \%)$ parents tended to have good interactions with their babies. The results of statistical tests obtained $p=0.0001$, concluding that there was a significant relationship between parental stress levels in terms of changes in the role of parents on the interaction between parents and their babies.

Based on the communication relationship between parents and health workers, there were three stressors felt by the mother, those are mother did not understand what is told by the nurse, nurses' delivered different information, and the mother became worried about the baby's condition because she did not understand the baby's actual condition. The analysis results of the relationship between parental stress levels in terms of communication and staff behavior towards parent-infant interactions. The research found that $18(51.4 \%)$ parents with low stress levels had lack of interaction with the baby. Meanwhile, among parents who had high stress levels, 33 (64.7\%) parents tended to have good interactions with their babies. The results of statistical tests obtained $p=0.0001$. It can be concluded that there was a significant relationship between parental stress level in terms of communication and staff behavior on the interaction of parents with their babies. In this case, health worker role is needed in decreasing the maternal stress by providing education to improve the maternal guidance skill of [18] as well as maternal preparedness to be discharged from hospital because Indonesian mothers have lower preparedness compared to the other countries mothers [19].

Mothers and parents will naturally interact directly with their babies shortly after birth. However, under certain conditions, this natural interaction process will not occur. Parents are forced to be separated from their babies if the newborn requires further action for saving their life, especially in cases of babies with severe complications, caesarean section, premature babies, and babies with low birth weight. This condition requires special and intensive care to meet the basic needs of the baby, especially the needs of oxygenation, warmth, nutrition, and prevention of infection. Separation between babies and parents, which is usually sudden, can cause stress for parents. 
It is not uncommon for parents to be in shock and prolonged sadness can even cause unconsciousness. This shock occurs, especially parents who do not have the heart to see the condition of their baby, leading to the parents become very worried about the safety of the baby who has been waiting for birth. This phenomenon occurs because it is affected by the coping of the mother (parents). Previous research by Sindun (2016) was conducted on coping mechanisms in dealing with stress in mothers whose babies were treated in NICU ward of Dr. M Djamil Padang. It showed that more than half $(55.2 \%)$ of mothers used coping mechanisms to focus on problems, while less than half $(44.8 \%)$ of mothers used coping mechanisms to focus on emotions [20].

Parents with high stress levels have a tendency to have positive interactions with their babies, such as paying attention to babies, showing feelings through facial expressions, touching and talking with babies, and eye contact with babies. These interactions are repeated by parents when they visit their babies. Meanwhile, parents with low stress levels feel less worried about their baby because it has been handled properly. They plan to do the roles of parents when the baby returns from the hospital. This makes the lack of good interaction between parents and their babies during the treatment process in NICU ward.

Demographically, there was no one demographic factor statistically affected maternal stress levels. Based on parity, there was no difference in stress levels between primiparous mothers and multiparous mothers, although the mean score of multiparous mothers was slightly higher on the subscale of the communication relationship between parents and nurses. Based on the experience of the cesarean section, there was no difference in the stress level of mothers who have never had SC with mothers who have had SC, even though the mean score of mothers who have had SC was slightly higher on subscales 1,3 , and 4 .

Among the four PSS: NICU subscales, the one with the highest mean value was the situation and scene in NICU. The results of this study are in line with the research conducted by Rahayuningsih (2016) which stated that the analysis results of the relationship between parental stress levels in terms of view and sounds in the NICU on the interaction between baby and parents showed that there were 26 (70.3\%) parents with low stress levels who had less interaction with the baby. Meanwhile, among parents who had high stress levels, $39(79.6 \%)$ parents tended to have good interactions with their babies. The statistical test results obtained $p=0.0001$, thus it can be concluded that there was a significant relationship between parental stress levels in terms of view and sounds in NICU on the interaction of parents with their babies.

Components that were considered as stressors included the sound alarm of monitors in
NICU ward and the number of health workers in the room. Based on the appearance and behavior of the baby, there were five stressors felt by the mothers, those are changes in baby skin color, baby size which was small, tube and needle attached to the baby's body, baby helpless look, and the baby who did not cry. Based on the sub-scale of the parent role, there were three sources of stressors felt by mothers; those are sadness due to being separated from the baby and feelings of helplessness and views of health workers who were closer to the baby than the mother. Based on the communication relationship between parents and health workers, there were two components felt by the mother as stressor, those are the mother who did not understand what is told by the nurse, nurses gave different information, and the mother became worried about the baby condition because she did not understand the baby actual condition even the mother is sometimes excluded from the ongoing communication and decision-making surrounding their baby [21]. To support parents, nurses need to understand more deeply about parent stress and coping and be able to distinguish between stress experienced by mothers and fathers in coping behaviors that appear when premature babies are treated at the NICU [22].

Research conducted by Holditch-David and Miles (2012) on the experiences of mothers of premature babies in NICU, performed an observation on inclusive health care providers in terms of the sources of maternal stress [23]. This study showed that health care providers, especially nurses, had a major role in reducing maternal stress by maintaining communication with mothers in providing competent care for premature infants who were admitted to the NICU.

\section{Conclusion}

Based on calculations using PSS: NICU, it was known that in terms of maternal stressors, higher levels of stressors occurred on situations and scenes in NICU, appearance and behavior of babies, role of parents, as well as communication relationship between parents and nurses. Meanwhile, demographic factors do not statistically affect maternal stressor.

\section{Acknowledgment}

We are thankful to the mothers of the preterm babies who took part in this study. 


\section{Ethical Statement}

This research is bound to the requirement from the Health Research Ethics Commission of Universitas Hasanuddin, Faculty of Medicine Makassar. Therefore, permission from committee and conditions was met and approved by the panel under the ethic category of "Human" approval number 958/UN4.6.4.5.31/ PP36/2019.

\section{References}

1. Agrawal R, Gaur A. Parent stress in neonatal intensive care unit: An unattended aspect in medical care. Int J Contemp Pediatr. 2016;4(1):148-53. https://doi.org/10.18203/2349-3291. ijcp20164596

2. Ashwani N, Rekha NA, Kumar CS. Parental stress experiences with NICU admission in a tertiary care centre. Int $\mathrm{J}$ Psychol Behav Sci. 2017;7(1):27-31.

3. Miles MS, Carter MC. Assessing parental stress in intensive care units. MCN Am J Matern Child Nurs. 1983;8(5):354-9. https://doi.org/10.1097/00005721-198309000-00014

4. Hunter J. Neonatal Intensive Care Unit. $4^{\text {th }}$ ed. St. Louis, MO: Mosby; 2001. p. 636-89.

5. Smithgall LM. Perceptions of Maternal Stress and Neonatal Patient Outcomes in a Single Private Room Versus Open Room Neonatal Intensive Care Unit Environment; 2010. https://doi. org/10.1111/j.1552-6909.2011.01242_103.x

6. Musabirema P, Brysiewicz P, Chipps J. Parents perceptions of stress in a neonatal intensive care unit in Rwanda. Curationis. 2015;38(2):1499. https://doi.org/10.4102/curationis.v38i2.1499 PMid:26842090

7. Sameroff AJ, Chandler MJ. Reproductive risk and the continuum of caretaking casualty. Rev Child Dev Res. 1975;4:187-244.

8. Busse M, Stromgren K, Thorngate L, Thomas KA. Parents' responses to stress in the neonatal intensive care unit. Crit Care Nurse. 2013;33(4):52-9. https://doi.org/10.4037/ccn2013715 PMid:23908169

9. Harvey ME. The Experiences and Perceptions of Fathers Attending the Birth and Immediate Care of Their Baby. United Kingdom: Aston University; 2010.

10. Syamsu A, Febriani A, Alasiry E, Erika K, Rustina Y. In: Hanaruddin DY, editor. Pedoman Asuhan Perkembangan Bayi Prematur Bagi Perawat NICU. Makassar: Isam Cahaya Publisher; 2020. p. 1-46.

11. Bostanabad MA, Areshtanab HN, Balila M, Jafarabadi MA, Ravanbakhsh K. Effect of a supportive-training intervention on mother-infant attachment. Iran J Pediatr. 2017;27(6):1. https://

\section{doi.org/10.5812/ijp.10565}

12. Fairus M, Widiyanti S. Relationship of husband's support with post-partum depression incidence in postpartum mothers. J Kesehatan Metro Sai Wawai. 2017;7(1):11-8. https://doi. org/10.26630/jkm.v11i1.1766

13. Qiftiyah M. Overview of the factors (family support, knowledge, pregnancy status and type of delivery) behind the post-partum blues incidence in postpartum mothers on the 7th day (at polindes doa ibu gesikharjo and polindes teratai kradenan palang). J Midpro. 2018;10(2):9-19. https://doi.org/10.30736/ midpro.v10i2.75

14. Gudruk KM, Champagne FA. Epigenetic effects of early developmental experiences. Clin Perinatol. 2011;38(4):703-17. PMid:22107899

15. Wong DL, Hockenberry-Eaton M, Wilson D, Winkeistein ML, Schawrtz P. Wong: Buku Ajar Keperawatan Pediatrik. $6^{\text {th }}$ ed. Jakarta: EGC; 2009.

16. Rahayu S, Nurhayati IA. Factors affecting parental stress levels on low birth weight (lbw) treated in neonate intensive care unit rsud dr. Moewardi in surakarta. J Keperawatan Glob. 2016;1(2):1-7. https://doi.org/10.37341/jkg.v1i2.22

17. Rahayuningsih SI. Parents' stress levels and interaction with their babies in the nicu room at rsudza banda aceh. Idea Nurs J. 2012;3(1):50-61.

18. Hariati S, Sutomo R, McKenna L, Reisenhofer S, Lusmilasari L, Febriani AD. Indonesian mothers' beliefs on caring practices at home for preterm babies after hospital discharge: A qualitative study. J Spec Pediatr Nurs. 2021;26(3):e12330. https://doi. org/10.1111/jspn.12330

PMid:33773015

19. Hariati S, Sutomo R, Lusmilasari L, Febriani ADB, Kadar K Discharge readiness of Indonesian mother with preterm infant in NICU. Enferm Clin. 2020;30 Suppl 2:234-7. https://doi. org/10.1016/j.enfcli.2019.07.096 PMid:32204154

20. Sindun S. Gambaran Mekanisme Koping Dalam Mengatas Stress Pada Ibu yang Memiliki Bayi BBLR Dalam Perawatan Di Ruang NICU RSUP Dr M Djamil Padang Tahun 2016. Indonesia: Universitas Andalas; 2016. https://doi.org/10.38040/ js.v11i01.79

21. Cockcroft $\mathrm{S}$. How can family centred care be improved to meet the needs of parents with a premature baby in neonatal intensive care? J Neonatal Nurs. 2012;18(3):105-10. https://doi. org/10.1016/j.jnn.2011.07.008

22. D'Souza SR, Karkada S, Lewis LE, Mayya S, Guddattu V. Relationship between stress, coping and nursing support of parents of preterm infants admitted to tertiary level neonatal intensive care units of Karnataka, India: A cross-sectional survey. J Neonatal Nurs. 2009;15(5):152-8. https://doi.org/10.1016/j. jnn.2009.07.003

23. Holditch-Davis D, Miles MS. Mothers' stories about their experiences in the neonatal intensive care unit. Neonatal Netw. 2000;19(3):13-21.https://doi.org/10.1891/0730-0832.19.3.13

PMid:11949060 